\title{
Mangrove changes analysis by remote sensing and evaluation of ecosystem service value in Sungai Merbok's Mangrove Forest Reserve, Peninsular Malaysia
}

\begin{abstract}
Mangrove forests are an important ecosystem which provides socioeconomic value to humankind. Despite their great value, mangroves have one of the highest rates of degradation of any global habitat, which is about $1 \%$ of the existing area per year. In fact, the socioeconomic value and ecosystem services of mangroves as a natural product are underestimated. The ecosystem services provided by mangroves are often ignored by the ongoing process of mangrove conversion. This is a major reason why conservation of this ecosystem is not a popular alternative. Thus, the main objective of this study is to evaluate the changes in mangrove forests and valuation of their ecosystem services. SPOT 5 imageries of years 2000 and 2010 have been used for change detection analysis. The vegetation index such as NDVI and AVI and unsupervised classification technique were employed in image processing. In order to obtain the value of socioeconomic impact from the mangrove changes and biodiversity disturbances, the ecosystem service valuation (ESV) model was applied. Results show that the total value of the existing mangrove forest ecosystem service was RM1,901,859.84. The value per unit area is about RM 1,650.92/ha. The total values of others were RM161, 33.2 (crop land) and RM3,107,500 (water bodies), respectively. It is evident that Sungai Merbokôs Mangrove Forest Reserve is very important for coastal ecology, where the orientation of mangrove ecosystem is huge and serves to provide essential services for the community. It also plays a crucial role in providing ecological balance to the coastal environment.
\end{abstract}

Keyword: Mangrove; Ecosystem service valuation; Changes detection; Remote sensing 